\title{
EDUCACIÓN
}

\section{Aprendizaje colaborativo con apoyo tecnológico}

\author{
Rosa Ruffinelli ${ }^{1}$ Lilian Domínguez², Míguela Hermosilla
}

\section{Resumen}

Introducción: El aprendizaje, tarea inherente al ser humano, no es una actividad en la que uno puede participar como mero espectador, de una manera inconsciente, se genera con participación directa y activa de los participantes, es decir de estudiantes y docentes. Todo proceso de aprendizaje se da con más efectividad cuando el mismo se realiza en equipo, y con mucha más efectividad cuando el equipo es colaborativo. La cooperación consiste en trabajar de manera integrada, todos juntos, en función a un objetivo común, en estas circunstancias se busca conseguir un resultado beneficioso para cada participante de forma individual, y para los demás, de forma grupal. El aprendizaje colaborativo surge a partir de la intencionalidad del docente, en fortalecer las relaciones ya existentes ente los estudiantes como herramientas para que el esfuerzo de cada uno se refleje en el resultado del trabajo desarrollado. El trabajo describe el aprendizaje colaborativo con apoyo de la tecnología en la Universidad Nacional de Asunción, Carrera de Enfermería, por medio de la incorporación al proceso de enseñanza - aprendizaje de las aplicaciones tecnológicas, como instrumento que propicia el trabajo colaborativo para el logro de las competencias en el curriculum vigente. Tal abordaje se plantea desde la perspectiva de que el conocimiento construido en forma colaborativa entiende al aprendizaje como un proceso social de construcción del conocimiento (más allá de la instancia individual de análisis, conceptualización y apropiación), aportando de esta forma como práctica social para una mejor inserción laboral, debido al modelo social (trabajar en equipo), que requiere de la habilidad de compartir el conocimiento para lograr una meta que trascienda las posibilidades individuales. Es decir, que a partir de este mecanismo guiado por el docente, hay un aprovechamiento por parte del estudiante que por intercambio de experiencias, habilidades y capacidades de cada miembro se genera y potencializa superlativamente este tipo de aprendizaje en función de las facilidades que brindan las nuevas tecnologías.

Objetivo: Presentar una experiencia de aprendizaje colaborativo, por medio del uso de tecnología, que permite un seguimiento y acompañamiento más efectivo de los trabajos propuestos por medio de la interacción entre los pares y el docente. Material y Método: Como metodología se utilizó la sistematización, como herramienta para investigar y producir conocimiento desde la experiencia en el aula; mediante el diseño teórico-metodológico que plantea los elementos

\footnotetext{
1. Instituto Andrés Barbero, Universidad Nacional de Asunción, Paraguay.

2. Instituto de Trabajo Social, Universidad Nacional de Asunción, Paraguay.

E-mail: rosaruffinelli@gmail.com

DOI: $10.26885 /$ rcei.foro.2017.91
} 
necesarios para organizar los conocimientos vinculados con docencia e investigación. Su propósito es incidir en el acto investigativo desde una perspectiva más social y científica e innovar en él, buscando nuevas fuentes que permitan hacer de la investigación una alternativa para impactar en una problemática en la búsqueda de soluciones viables para la misma.

Resultados: A partir de la indagación realizada se evidencia la necesidad de: Crear espacios de confianza entre los estudiantes, lograr un lenguaje común entre los docentes, favorecer las practicas intergeneracionales, desarrollar conocimientos básicos indispensables, generar infraestructura necesaria y articular planes de estudio. Uno de los principales aportes visibilizados a partir de esta experiencia es que se da un mayor desarrollo de competencias comunicativas, trabajo en equipo y autonomía en comparación con el método tradicional, ya que el estudiante está en el centro del proceso educativo haciéndose él protagonista principal de su formación profesional y logrando aprendizajes más significativos. Por otra parte, los ambientes educativos que se apoyan en la virtualidad, la información ya no se localiza en un único lugar predeterminado, rompiéndose así las barreras espacio-temporales y dando paso a un nuevo modo de construir el conocimiento, en el que se requiere el trabajo cooperativo para la resolución de dudas y comprensión de ideas, en un espacio que no es solamente el aula, sino la cotidianeidad, que permite una relación más fluida y menos artificial del conocimiento aprehendido. Por otra parte, el aprendizaje colaborativo permite zanjar las brechas tecnológicas entre pares, surgidas a partir de procesos de formación diferentes, condicionado por la pluralidad de pertenencias, ya que los estudiantes provienen de grupos sociales, ámbitos y situaciones diferentes. A partir de esta sistematización instamos a las unidades académicas promover la utilización del proceso de aprendizaje colaborativo con apoyo de las tecnologías de comunicación, que se constituyen en un recurso didáctico muy valioso, de fácil acceso para el docente, y de excelencia para el desarrollo y el aprendizaje continuo y significativo del estudiante.

Palabras clave: conocimiento, tecnología, aprendizaje colaborativo.

\section{Referencias}

Álvarez de Eulate, C. Y. (2013). Planificar desde competencias para promover el aprendizaje: el reto de la sociedad del conocimiento para el profesorado universitario. sl: Publicaciones de la Universidad de Deusto.

Barkley, E., Manzano, P., Major, C. \& Cross, K. (2012). Técnicas de aprendizaje colaborativo: Manual para el profesorado universitario (e-book). Madrid: Ediciones Morata.

Olmos Migueláñez, S. \& Hernández Martín, A. (2011). Metodologías de aprendizaje colaborativo a través de las tecnologías. Salamanca: Ediciones Universidad de Salamanca. 